\title{
Exploitation of Unconventional Electrophiles in Enantioselective Pd(0)-Catalyzed C-H Functionalizations
}

\author{
Daria Grosheva ${ }^{\S}$ and Nicolai Cramer \\ §SCS-Metrohm Award for best oral presentation in Organic Chemistry
}

\begin{abstract}
Asymmetric metal-catalyzed $\mathrm{C}-\mathrm{H}$ functionalization is a powerful strategy for the rapid generation of complex target molecules from simple precursors. While aryl (pseudo)halides have been used as electrophilic substrates in enantioselective $\mathrm{Pd}(0)$-catalyzed syntheses of $\mathrm{N}$-heterocycles, alternative partners for $\mathrm{C}-\mathrm{H}$ functionalizations remain underexplored. Herein we describe the first application of ketene aminal phosphates as competent electrophiles in a $\mathrm{Pd}(0)$-catalyzed desymmetrization. This transformation allowed the efficient synthesis of chiral isoindolines in a highly enantioselective fashion. Furthermore, intending to introduce sought-after perfluoroalkyl substituents, we explored intramolecular $\mathrm{C}-\mathrm{H}$ functionalization of imidoyl chlorides resulting in the asymmetric preparation of previously inaccessible $1 \mathrm{H}$-isoindoles. Tailored chiral monodentate ligands afforded high levels of enantioinduction in both transformations.
\end{abstract}

Keywords: Asymmetric catalysis · C-H functionalization · Heterocycles · Ligand design · Palladium

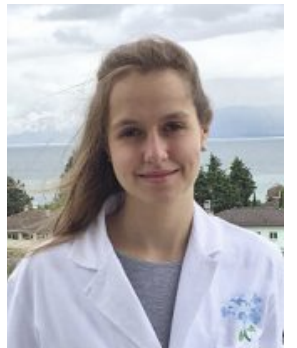

Daria Grosheva was born and raised in Saint Petersburg, Russia. While completing her Specialist of Chemistry degree at $\mathrm{St}$ Petersburg University she conducted a summer internship at the University of Texas at San Antonio with Prof. Oleg Larionov and a research stay at Ecole Polytechnique, Paris, with Dr. Yvan Six, supported by a Scholarship of the President of Russian Federation. Daria commenced her doctoral studies at the group of Prof. Cramer in late 2014, working on the development of asymmetric Pd-catalyzed $\mathrm{C}-\mathrm{H}$ functionalizations. In mid-2019 she will join the Hyster group at Princeton University as an SNF Postdoctoral Fellow.

\section{Introduction}

Over the past decade, metal-catalyzed $\mathrm{C}-\mathrm{H}$ functionalization has become a key research area in synthetic organic chemistry. ${ }^{[1]}$ In particular, the stereocontrolled functionalization of $\mathrm{C}-\mathrm{H}$ bonds has emerged as a powerful tool for the rapid construction of elaborate structures from simple and readily available starting materials. ${ }^{[2]}$ For example, the enantioselective synthesis of $N$-heterocycles by $\mathrm{Pd}(0)$-catalyzed direct arylation has been extensively explored, typically employing aryl (pseudo)halides as electrophilic substrates (Scheme 1). ${ }^{[3]}$ Related asymmetric $\mathrm{C}-\mathrm{H}$ alkenylations, ${ }^{[4]}$ alkylations ${ }^{[5]}$ and imidoylations ${ }^{[6]}$ remain far less developed, resulting in the confined scope of the obtainable products. We aimed to explore unconventional electrophilic partners in order to access a broader diversity of elaborate $N$-heterocyclic scaffolds.

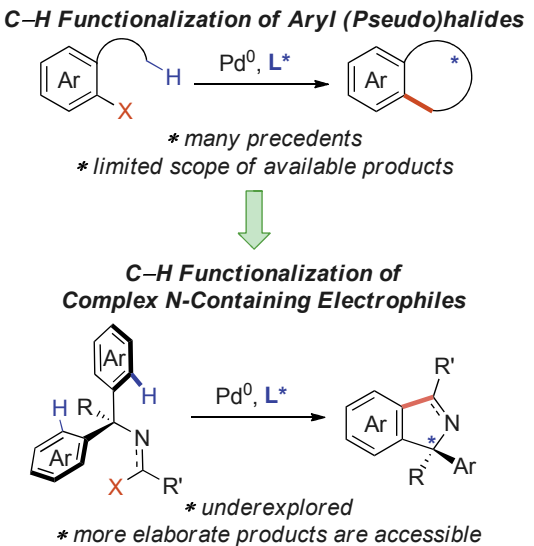

Scheme 1. Aryl (pseudo)halides vs complex $N$-containing electrophiles for asymmetric $\mathrm{Pd}(0)$-catalyzed $\mathrm{C}-\mathrm{H}$ functionalizations.

\section{Results and Discussion}

\section{Synthesis of Chiral Electron-Rich Monodentate Phosphine Ligands ${ }^{[7]}$}

Efforts towards successful development of enantioselective metal-catalyzed transformations, including $\mathrm{Pd}(0)$-catalyzed $\mathrm{C}-\mathrm{H}$ functionalizations, go hand-in-hand with the design of suitable chiral ligands. Mechanistically, while the oxidative addition of electrophiles to $\operatorname{Pd}(0)$ complexes at ambient temperature is accelerated by electron-rich phosphines, the concerted metalationdeprotonation $(\mathrm{CMD})$ step requires a monoligated $\mathrm{Pd}(0)$ species (Scheme 2). Overall, a successful catalytic asymmetric process is, therefore, favored by a ligand combining both properties; however, only a limited range of efficient chiral electron-rich monodentate phosphines is currently available.

Available chiral electron-rich monodentate phosphines include the SagePhos ligand family, previously developed in the Cramer group; it combines a 2',6'-dialkoxybiaryl core with the $C_{2}$ symmetric electron-rich phospholane moiety (Scheme 3). [3d] In 


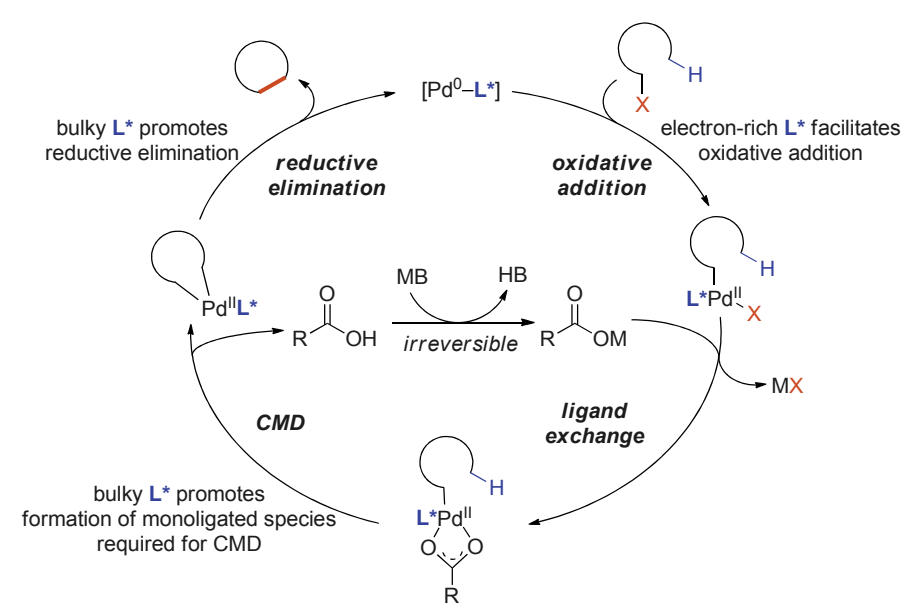

Scheme 2. Generic catalytic cycle for $\mathrm{Pd}(0)$-catalyzed $\mathrm{C}-\mathrm{H}$ functionalization.

order to have an extra handle for further reactivity and selectivity tuning, we sought to introduce an additional modification position in the SagePhos scaffold; namely, the powerful atrop-chiral biaryl unit of the MOP ligand. ${ }^{[8]}$ The synthesis of methoxy-substituted ligand $\mathbf{L 1}$ has been reported; ${ }^{[9]}$ however, the previous approach is low yielding and rather inconvenient, and while it was suitable for the preparation of a single member of the ligand family, it did not fit our purpose of generating a small library of BINOLderived phosphines. To this end, our strategy was based on the $\operatorname{Pd}(0)$-catalyzed coupling of BINOL bis-triflate $(R)-\mathbf{1}$ or $(S)-\mathbf{1}$ with secondary phosphine oxide $\mathbf{2}$, which resulted in the selective formation of products 3 or $\mathbf{4}$. Saponification of the triflyl moiety revealed the hydroxyl group, which was alkylated or silylated with a substituent of variable steric demand. Finally, reduction of phosphine oxide moiety with $\mathrm{Cl}_{3} \mathrm{SiH}$ gave access to bulky monodentate ligands $\mathbf{L 1}-\mathbf{L 6}$, as well as their diastereoisomeric counterparts $\mathbf{L 7}$ and $\mathbf{L 8}$. The overall route proved to be scalable, reproducible and divergent with respect to the introduction of the substituent $\mathrm{R}$ on the lower aryl ring of the ligand scaffold.

\section{Asymmetric C-H Functionalization of Ketene Aminal Phosphates ${ }^{[7]}$}

Regarding the reaction development, we first envisioned a methodology based on the $\operatorname{Pd}(0)$-catalyzed desymmetrization of ketene aminal electrophiles delivering fused $N$-heterocycles (Scheme 4). We chose ketene aminal phosphates as substrates as they can be readily accessed by deprotonation of the corresponding imides and trapping with a phosphoryl chloride. ${ }^{[10]}$ Moreover, in stark contrast to ketene aminal triflates, the corresponding phosphates are stable compounds that could be isolated and characterized. ${ }^{[10,11]}$ We were also interested whether the built-in phosphate moiety could serve as a competent base in the concerted metalation-deprotonation step and what influence it would have on the enantioselectivity of the process. Finally, the successful alkenylation followed by functional group manipulations would afford enantioselective access via a new disconnection to the valuable indolizidine scaffold that is present in many natural products.

Phenyl-substituted ketene aminal phosphate 5a was chosen as the prototype substrate and the system including $\mathrm{Pd}(\mathrm{dba})_{2}, 2,2$-diphenylpropionic acid and $\mathrm{Cs}_{2} \mathrm{Co}_{3}$ was identified as the optimal set of reaction conditions after the preliminary optimization studies. With newly developed phospholanes L1-L6 a general trend was observed: introducing a bulkier substituent $\mathrm{R}$ on the ligand backbone resulted in higher enantioselectivities, accompanied by a loss in reactivity; and TBDPS-substituted ligand L6 was the most selective (Table 1, entries 1-6). When axially diastereoisomeric phosphines L7 and L8 were employed, the enantioselectivities slightly dropped, suggesting that the axial chirality of the ligand scaffold has a minor influence on the selectivity, and the dominant portion of enantioinduction primarily arises from the dimethyl phospholane unit (entries 7 and 8). This hypothesis was further

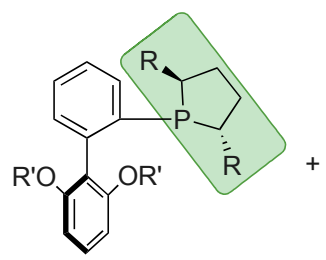

SagePhos point chirality

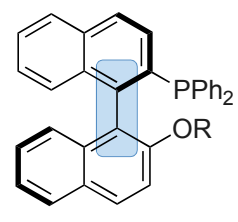

MOP axial chirality

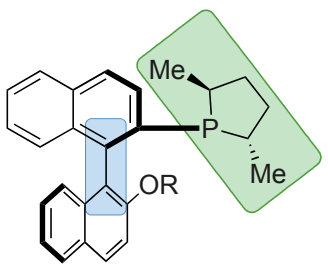

Flexible Scaffold point+axial chirality

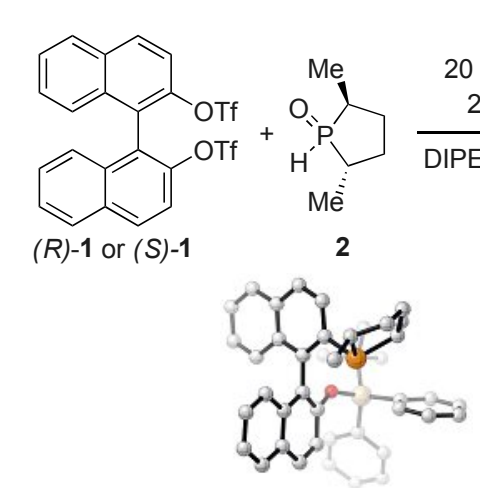

X-Ray structure of L6 $(R, S, S)$

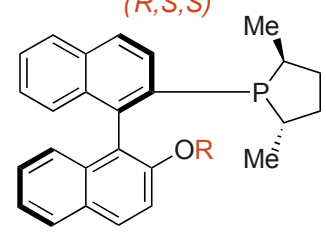

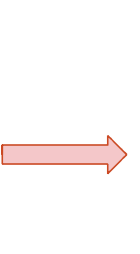

.

.

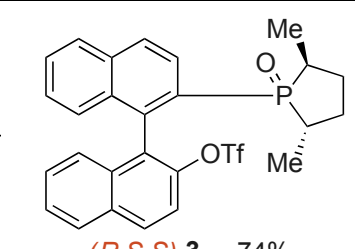

1) $\mathrm{NaOH}, \mathrm{MeOH}$

2) $R X$, base $\left(S_{N} 2\right)$ or $\mathrm{ROH}$ (Mitsunobu) $20 \mathrm{~mol} \% \mathrm{dppb}$ A, PhMe, DMSO $110^{\circ} \mathrm{C}, 48 \mathrm{~h}$

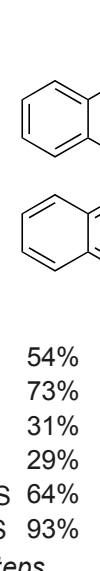

(R,S,S)-3 74\% (S, S, S) $-4 \quad 58 \%$<smiles>[R20]c1ccc2ccccc2c1-c1c(P2[C@H](C)CC[C@H]2C)ccc2ccccc12</smiles>

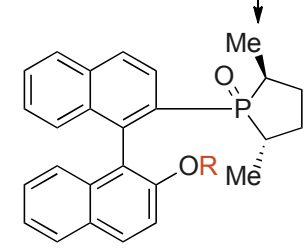

$$
\begin{array}{lll}
\text { L1 } & \text { Me } & 54 \% \\
\text { L2 } & i \mathrm{Pr} & 73 \% \\
\text { L3 } & \text { Cy } & 31 \% \\
\text { L4 } & \text { CHPh }_{2} & 29 \% \\
\text { L5 } & \text { TBDMS } & 64 \% \\
\text { L6 } & \text { TBDPS } & 93 \% \\
\multicolumn{4}{c}{\text { over } 3 \text { steps }}
\end{array}
$$

$(S, S, S)$

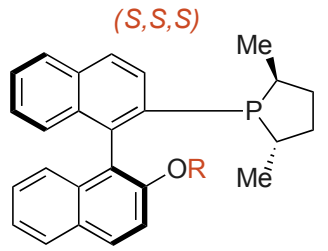

L7 $i \mathrm{Pr} \quad 48 \%$

L8 TBDPS 55\%

over 3 steps
Scheme 3. Design and synthesis of chiral electron-rich monodentate ligands L1-L8. 
Scheme 4. Enantioselective C-H functionalization of ketene aminal phosphates.
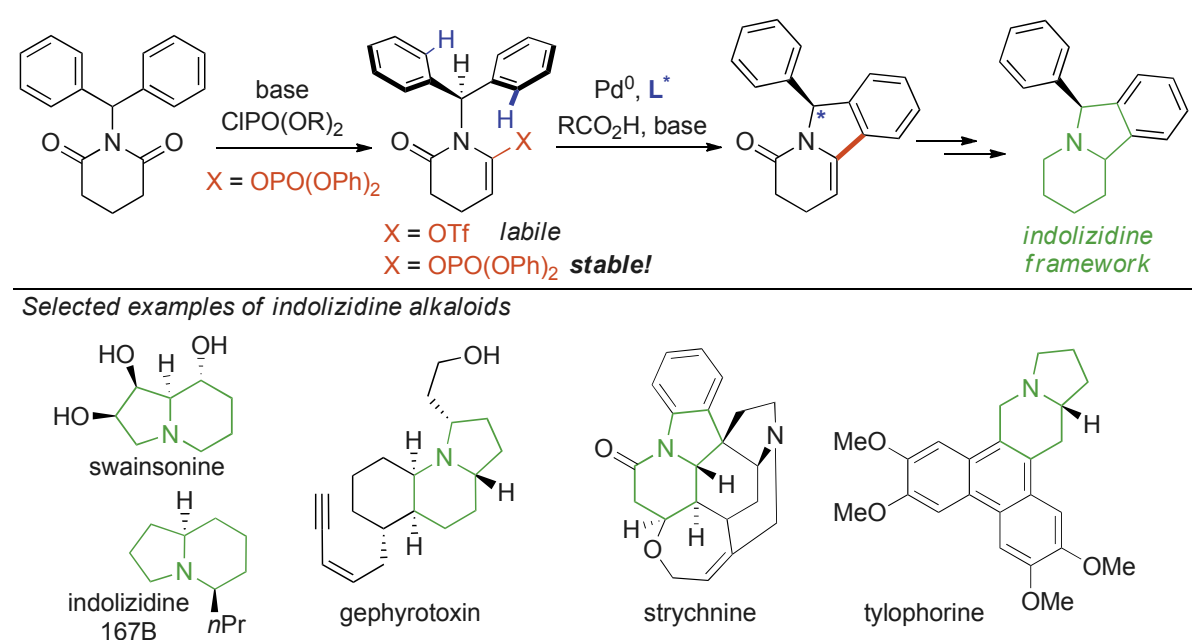

proved when the reaction with axially chiral Cy-MOP resulted in a virtually racemic formation of the desired product (entry 9), in striking contrast to the highly enantioselective transformation enabled by SagePhos-type ligand L10 (entry 10). Notably, more electron-poor TADDOL-derived phosphoramidites L11 and L12 that have provided for a number of asymmetric $\operatorname{Pd}(0)$-catalyzed $\mathrm{C}-\mathrm{H}$ functionalizations ${ }^{[12]}$ required higher reaction temperature and displayed only modest enantiocontrol (entries 11 and 12). The selectivity of the transformation could be improved by using benzoic or pivalic acids (entries 13 and 14). Carrying out a reaction under carboxylate-free conditions (carboxylate-free Pd source and no external carboxylic acid) we tested the hypothesis on the phosphate anion acting as a base in the CMD step. Conversion and enantioselectivity were inferior compared to the original conditions, suggesting the diphenyl phosphate was a poor promotor of the concerted metalation-deprotonation process (entry 15). Replacing $\mathrm{Pd}(\mathrm{dba})_{2}$ with $\mathrm{Pd}(\mathrm{OAc})_{2}$ resulted in a faster reaction, albeit with lower enantioselectivity: the presence of acetate most likely influenced the selectivity of the enantiodetermining CMD step (entry 16). Employing commercially available $\mathrm{Pd}(\mathrm{OPiv})_{2}$ circumvented this issue and allowed for an efficient and highly enantioselective transformation at ambient temperature with the catalyst loading reduced to $5 \mathrm{~mol} \%$ of palladium precursor (entry 17). The nature of the employed phosphate ester was crucial for the reactivity: thus, diethyl phosphate $\mathbf{5} \mathbf{a}^{\prime}$ remained inert, even at an elevated temperature of $80^{\circ} \mathrm{C}$ (entry 18). Finally, the transformation could be carried out on a larger scale, delivering $1.05 \mathrm{~g}$ of isoindoline 6a without affecting the enantioselectivity (entry 19).

With the optimal conditions in hand, we evaluated the scope and limitations of the transformation (Scheme 5). Electron-poor and electron-rich substrates could be functionalized delivering corresponding heterocycles $\mathbf{6 b}$ and $\mathbf{6 c}$ in comparable yields and similar enantioselectivities. Furthermore, an aryl chloride moiety in substrate $\mathbf{5 d}$ remained intact during the Pd-catalyzed transformation, allowing for a potential orthogonal late-stage functionalization. The cyclizations of meta-substituted substrates $\mathbf{5 e}$ and 5 f proceeded with a remarkable level of regioselectivity, and the more accessible ortho-C-H groups were functionalized exclusively. The substrate featuring electron-rich thiophene was well tolerated, and the corresponding heterocycle $\mathbf{6} \mathbf{g}$ was furnished in excellent enantioselectivity. ortho-Substituted substrates (e.g. 5h) could also be functionalized, however, in this case, higher reaction temperature was required, resulting in reduced enantioselectivity of the obtained isoindoline. Spirocyclic ketene aminal phosphate $\mathbf{5 i}$ was efficiently functionalized at ambient temperature, but with somewhat reduced selectivity.

The alkenyl moiety in isoindoline $\mathbf{6 a}$ could be selectively hydrogenated from the more accessible site, delivering a single diastereoisomer of lactam 7a (Scheme 6). Subsequent nickel-
Table 1. Optimization of the enantioselective isoindoline synthesis.

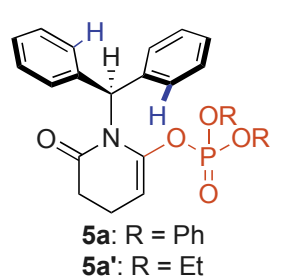
$10 \mathrm{~mol} \%$ [Pd], $20 \mathrm{~mol}^{\mathrm{O}} \mathrm{L}^{*}$ $\mathrm{R}^{\prime} \mathrm{CO}_{2} \mathrm{H}, \mathrm{Cs}_{2} \mathrm{CO}_{3}$ $\mathrm{PhMe}, 40^{\circ} \mathrm{C}, 12 \mathrm{~h}$
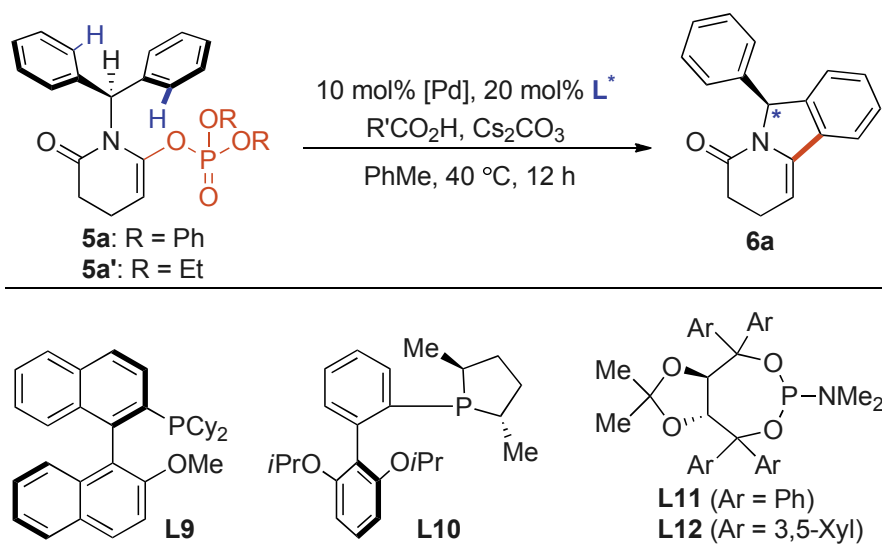

\begin{tabular}{|c|c|c|c|c|c|}
\hline Entry & [Pd] & $\mathbf{L}^{*}$ & Acid & $\begin{array}{l}\text { Yield } \\
\text { of } 6 a^{a}\end{array}$ & er \\
\hline 1 & $\operatorname{Pd}(\mathrm{dba})_{2}$ & $\mathbf{L 1}$ & $\mathrm{Ph}_{2} \mathrm{MeCCO}_{2} \mathrm{H}$ & $78 \%$ & 78.5:21.5 \\
\hline 2 & $\mathrm{Pd}(\mathrm{dba})$ & $\mathbf{L} 2$ & $\mathrm{Ph}_{2} \mathrm{MeCCO}_{2} \mathrm{H}$ & $65 \%$ & $87: 13$ \\
\hline 3 & $\mathrm{Pd}(\mathrm{dba})_{2}$ & $\mathbf{L 3}$ & $\mathrm{Ph}_{2} \mathrm{MeCCO}_{2} \mathrm{H}$ & $48 \%$ & $87: 13$ \\
\hline 4 & $\mathrm{Pd}(\mathrm{dba})_{2}$ & L4 & $\mathrm{Ph}_{2} \mathrm{MeCCO}_{2} \mathrm{H}$ & $32 \%$ & 90:10 \\
\hline 5 & $\mathrm{Pd}(\mathrm{dba})_{2}$ & L5 & $\mathrm{Ph}_{2} \mathrm{MeCCO}_{2} \mathrm{H}$ & $16 \%$ & $77.5: 22.5$ \\
\hline 6 & $\mathrm{Pd}(\mathrm{dba})_{2}$ & L6 & $\mathrm{Ph}_{2} \mathrm{MeCCO}_{2} \mathrm{H}$ & $29 \%$ & $90.5: 9.5$ \\
\hline 7 & $\mathrm{Pd}(\mathrm{dba})_{2}$ & L7 & $\mathrm{Ph}_{2} \mathrm{MeCCO}_{2} \mathrm{H}$ & $43 \%$ & $70: 30$ \\
\hline 8 & $\mathrm{Pd}(\mathrm{dba})_{2}$ & $\mathbf{L 8}$ & $\mathrm{Ph}_{2} \mathrm{MeCCO}_{2} \mathrm{H}$ & $38 \%$ & $86.5: 13.5$ \\
\hline 9 & $\mathrm{Pd}(\mathrm{dba})_{2}$ & L9 & $\mathrm{Ph}_{2} \mathrm{MeCCO}_{2} \mathrm{H}$ & $19 \%$ & $51: 49$ \\
\hline 10 & $\mathrm{Pd}(\mathrm{dba})_{2}$ & L10 & $\mathrm{Ph}_{2} \mathrm{MeCCO}_{2} \mathrm{H}$ & $82 \%$ & 89:11 \\
\hline $11^{\mathrm{b}}$ & $\mathrm{Pd}(\mathrm{dba})_{2}$ & L11 & $\mathrm{Ph}_{2} \mathrm{MeCCO}_{2} \mathrm{H}$ & $12 \%$ & $70.5: 29.5$ \\
\hline $12^{\mathrm{b}}$ & $\mathrm{Pd}(\mathrm{dba})_{2}$ & L12 & $\mathrm{Ph}_{2} \mathrm{MeCCO}_{2} \mathrm{H}$ & $60 \%$ & $79.5: 20.5$ \\
\hline 13 & $\mathrm{Pd}(\mathrm{dba})_{2}$ & L6 & $\mathrm{PhCO}_{2} \mathrm{H}$ & $37 \%$ & 93:7 \\
\hline 14 & $\mathrm{Pd}(\mathrm{dba})_{2}$ & L6 & $\mathrm{PivOH}$ & $36 \%$ & $93.5: 6.5$ \\
\hline 15 & $\mathrm{Pd}(\mathrm{dba})_{2}$ & L6 & - & $21 \%$ & $73: 27$ \\
\hline 16 & $\mathrm{Pd}(\mathrm{OAc})_{2}$ & L6 & $\mathrm{PivOH}$ & $82 \%$ & $75.5: 24.5$ \\
\hline $17^{\mathrm{c}}$ & $\mathrm{Pd}(\mathrm{OPiv})_{2}$ & L6 & PivOH & $93 \%$ & 94.5:5.5 \\
\hline $18^{\mathrm{c}, \mathrm{d}}$ & $\mathrm{Pd}(\mathrm{OPiv})_{2}$ & L6 & $\mathrm{PivOH}$ & $8 \%$ & $\begin{array}{l}\text { not deter- } \\
\text { mined }\end{array}$ \\
\hline $19^{\mathrm{e}}$ & $\mathrm{Pd}(\mathrm{OPiv})_{2}$ & L6 & $\mathrm{PivOH}$ & $80 \%$ & $95.5: 4.5$ \\
\hline
\end{tabular}

a Determined by ${ }^{1} \mathrm{H}$ NMR with an internal standard. bAt $80^{\circ} \mathrm{C}$. 'With 5 mol\% Pd(OPiv) ${ }_{2}, 10$ mol\% L6 at $0.5 \mathrm{M}$ and $23{ }^{\circ} \mathrm{C}$. ${ }^{\mathrm{d}} \mathbf{5} \mathbf{a}^{\prime}$ instead of $5 \mathbf{a}$ at $80{ }^{\circ} \mathrm{C}$. ${ }^{\mathrm{e}} 5 \mathrm{mmol} 5 \mathrm{a}$ [2.56 g], 5 mol\% Pd(OPiv) $)_{2}, 10 \mathrm{~mol} \%$ L6, $7.5 \mathrm{mmol}$ $\mathrm{Cs}_{2} \mathrm{CO}_{3}, 0.5 \mathrm{M}$ in PhMe, at $23^{\circ} \mathrm{C}$ for $48 \mathrm{~h}$. 

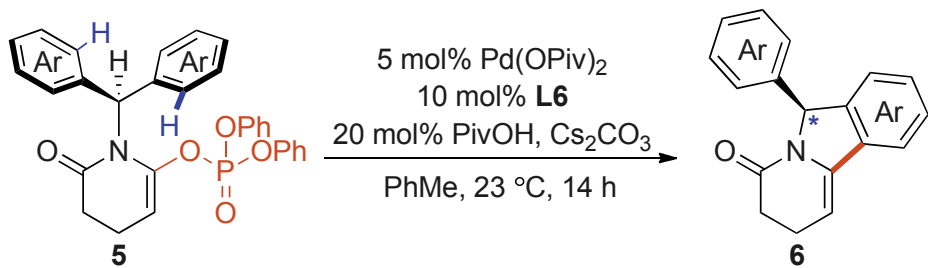

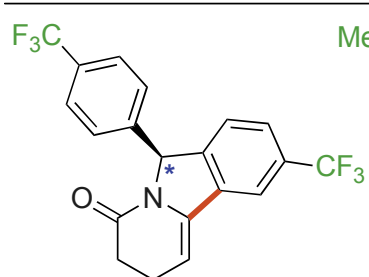

$6 \mathrm{~b}$

$79 \%, 97: 3$ er

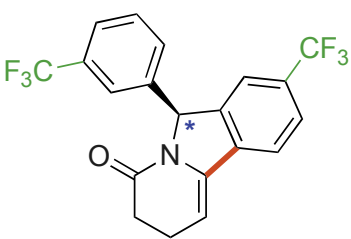

$6 f$

$88 \%, 92: 8 \mathrm{er}^{[\mathrm{a}]}$

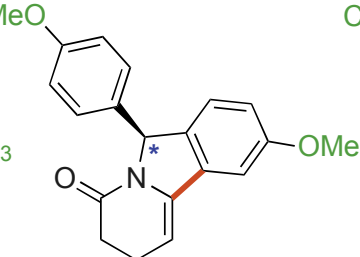

$6 \mathrm{c}$

$82 \%, 94.5: 5.5 \mathrm{er}$

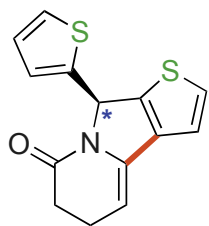

$6 \mathrm{~g}$

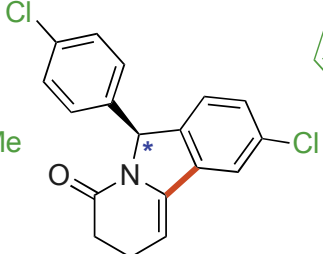

6d

$76 \%, 94.5: 5.5 \mathrm{er}^{[\mathrm{a}]}$

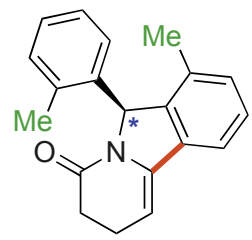

6h

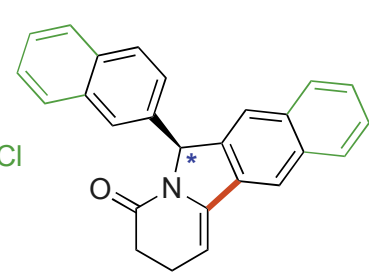

$6 \mathrm{e}$

$73 \%, 89: 11 \mathrm{er}^{[\mathrm{a}]}$

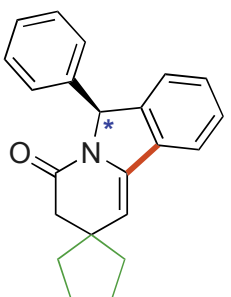

$59 \%, 96: 4 \mathrm{er}^{[\mathrm{a}]}$

$6 i, 82 \%, 85.5: 14.5$ er

Scheme 5. Selected scope entries of the asymmetric ketene aminal phosphate cyclization. ${ }^{[a]}$ With 10 mol\% Pd(OPiv)2, 20 mol\% L6. ${ }^{[b]}$ At $60^{\circ} \mathrm{C}$.

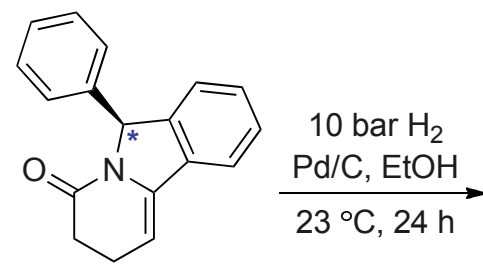

$6 a$

$98: 2$ er

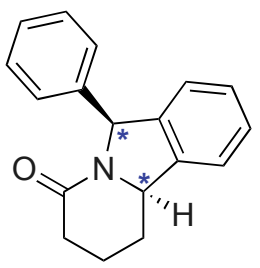

$7 a$

$71 \%,>20: 1 \mathrm{dr}$ $98: 2$ er

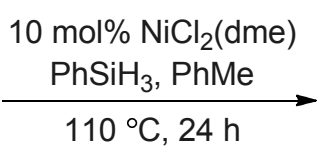

$110^{\circ} \mathrm{C}, 24 \mathrm{~h}$

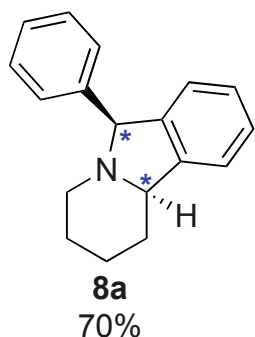

$70 \%$

Scheme 6. Two-step preparation of indolizidine 8a

catalyzed amide reduction with phenylsilane ${ }^{[13]}$ afforded tertiary amine 8a featuring the sought-after indolizidine scaffold.

\section{Enantioselective Synthesis of Perfluoroalkyl- Substituted 1H-Isoindoles[14]}

Having developed an enantioselective approach toward isoindolines, we aspired to employ $\mathrm{Pd}(0)$-catalyzed $\mathrm{C}-\mathrm{H}$ functionalization to access other types of $\mathrm{N}$-heterocycles, namely, $1 \mathrm{H}$-isoindoles. The isoindole framework is found in natural products, pharmaceuticals and materials (Scheme 7). ${ }^{[15]}$ However, synthetic approaches to $1 \mathrm{H}$-isoindoles remain largely limited to conventional methods. ${ }^{[16]}$ As active molecules often contain stereogenic centers, catalytic asymmetric strategy to access $1 H$-isoindoles would be highly desirable. We proposed an approach based on the intramolecular enantioselective $\mathrm{C}-\mathrm{H}$ functionalization of perfluoroalkyl-substituted imidoyl chlorides, electrophilic partners, which were introduced by Uneyama, ${ }^{[17]}$ and subsequently probed in an asymmetric functionalization by our group. ${ }^{[6 b]}$ If successful, our strategy would allow for an introduction of the quaternary stereogenic center, furnishing an attractive three-dimensional framework with functional exit vectors. Employing perfluoroalkylated imidoyl chlorides as substrates would result in the introduction of a perfluoroalkyl substituent in the product. Given the interest in fluorine-containing compounds in active-ingredient discovery, ${ }^{[18]}$ the construction of such patterns would be an additional advantage of the approach.
Furthermore, while several methods enabling synthesis of perfluoroalkylated isoindolines have been reported, ${ }^{[19]}$ the corresponding $1 \mathrm{H}$-isoindoles bearing this appealing substitution pattern remain inaccessible through conventional methods. ${ }^{[16 a]}$

The initial ligand screening was carried out with isopropyl-substituted imidoyl chloride 9a (Scheme 8). The standard TADDOL-derived ligands L11-L13 provided the desired product in excellent yields, albeit, with only modest enantioselectivities. When we switched to the use of bulky diazaphospholane ligands L14-L16 developed in the Cramer group previously, ${ }^{[20]}$ the reaction was operating already at $40{ }^{\circ} \mathrm{C}$. Methoxy-substituted diazaphospholane $\mathbf{L 1 6}$ bearing 1-naphthyl and tert-butyl groups on the chiral flanking arms was the ligand of choice and resulted in a highly enantioselective transformation. The catalyst loading could be lowered to $5 \mathrm{~mol} \%$ of $\operatorname{Pd}(\mathrm{dba})_{2}$ with the reaction time prolonged to 36 hours.

In regard to the scope of the transformation, a wide variety of substrates were well-tolerated (Scheme 9). Again, electron-rich and electron-poor substrates reacted well, however, the functionalization of para-methoxy substituted imidoyl chloride 9c required longer reaction time, which is consistent with a CMDtype activation mechanism. ${ }^{21]}$ Selective functionalization of 2-naphthyl-substituted trifluoroacetimidoyl chloride delivered 10d featuring the extended aromatic system of $1 H$-benzo[f] isoindole. Substrate 9e, bearing electron-rich thienyl substitu- 

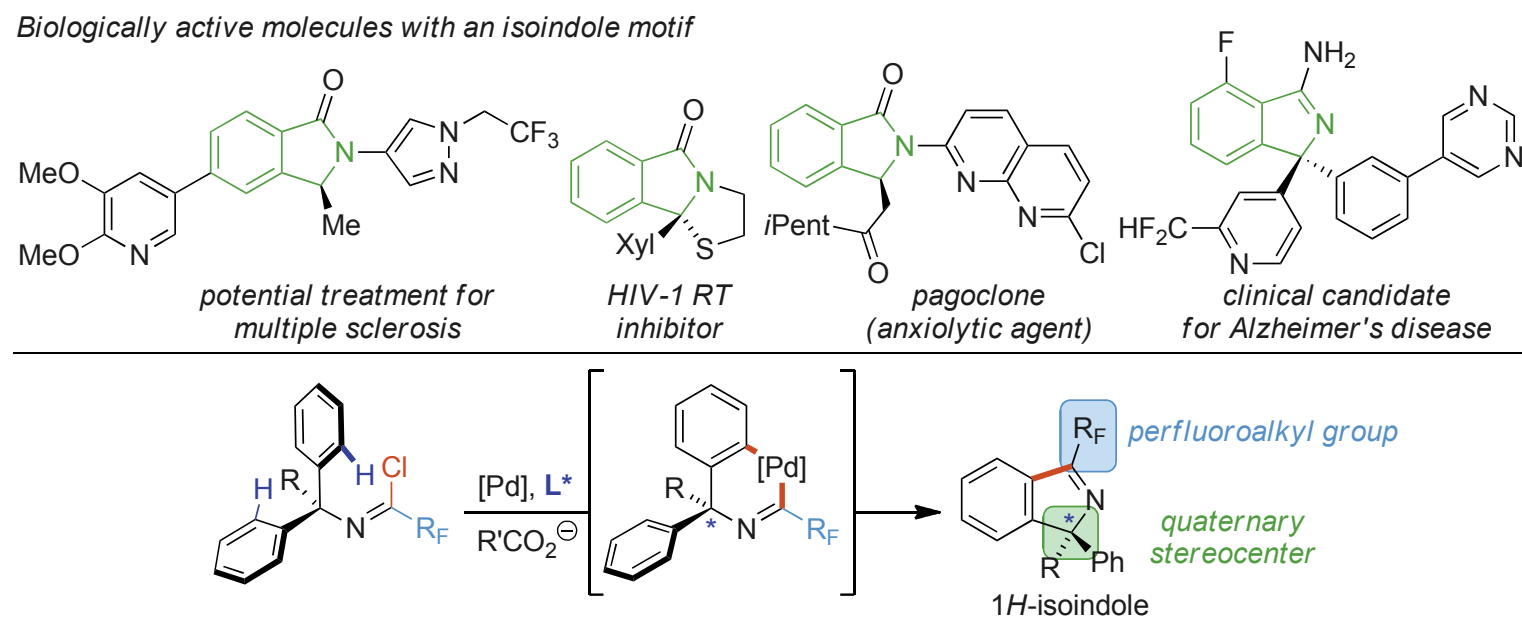

Scheme 7. Enantioselective $\mathrm{C}-\mathrm{H}$ functionalization approach toward chiral $1 \mathrm{H}$-isoindoles.

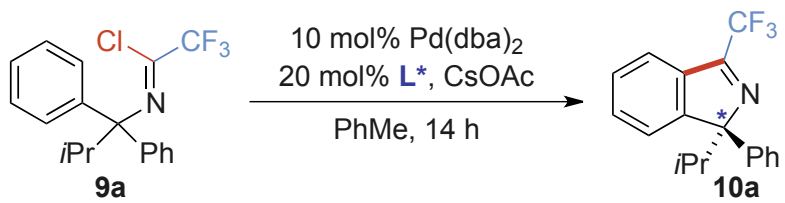

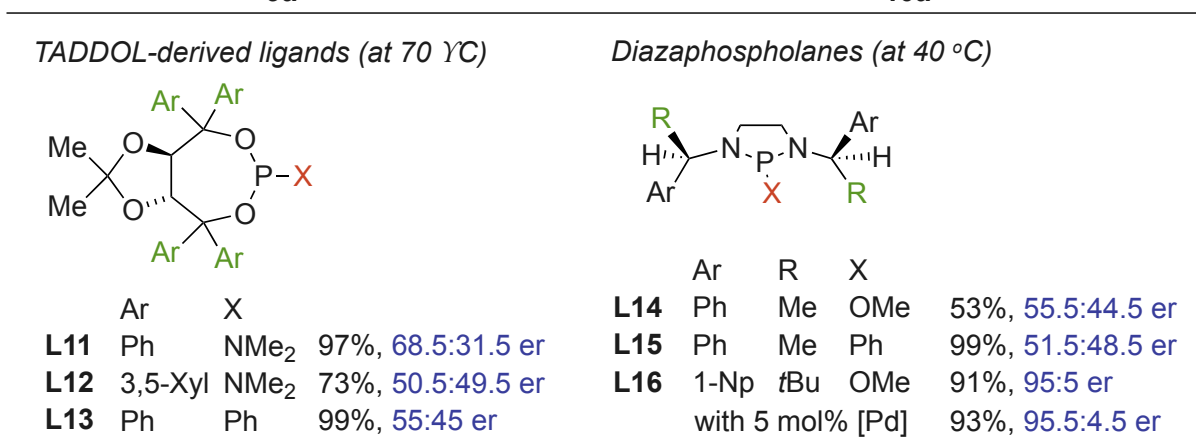

Scheme 8. Optimization of the enantioselective $\mathrm{C}-\mathrm{H}$ functionalization of trifluoroacetimidoyl chloride.

ents, was efficiently functionalized, and the corresponding thienopyrrole 10e was obtained in excellent enantioselectivity. Moreover, X-ray analysis of 10e enabled the assignment of the absolute configuration. Imidoyl chlorides homologated with longer perfluoroalkylated chains reacted equally well, and the corresponding thienopyrroles $\mathbf{1 0 f}$ and $\mathbf{1 0 g}$ were obtained with comparable levels of yield and enantioselectivity. Various alkyl groups on the quaternary stereocenter were well-tolerated. For example, cyclopropyl-substituted imidoyl chloride $\mathbf{9 h}$ was cyclized with excellent chemoselectivity, and no product of competing $\mathrm{C}\left(\mathrm{sp}^{3}\right)-\mathrm{H}$ functionalization was observed. Functionalized substituents could also be introduced: azetidinyl-substituted
Scheme 9. Selected scope entries of the asymmetric $1 \mathrm{H}$-isoindole synthesis. ${ }^{[a]}$ Reaction time: $80 \mathrm{~h}$. [b]10 mol\% Pd(dba)2, 20 mol\%

L16.

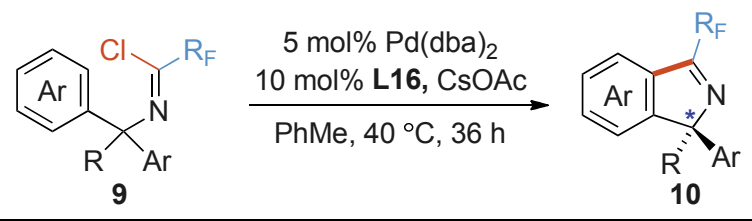

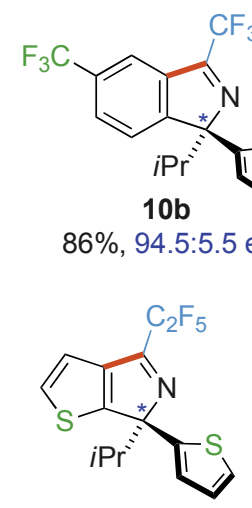

$10 f$

$81 \%, 96.5: 3.5 \mathrm{er}^{[\mathrm{b}]}$

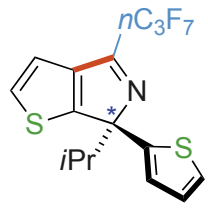

$10 \mathrm{~g}$<smiles>CCCCCCC(=O)Oc1ccc([C@]2(c3ccc(OC)cc3)N=C(C(F)(F)F)c3cc(OC)ccc32)cc1</smiles><smiles>CC(C)[C@]1([Y6]#N)N=C(C(F)(F)F)c2cc3ccccc3cc21</smiles>

$10 \mathrm{~d}$

$87 \%, 95: 5 \mathrm{er}^{[\mathrm{b}]}$
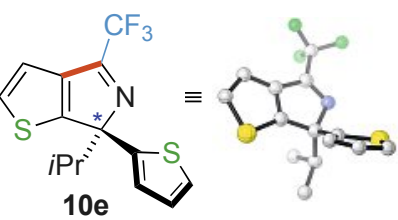

$84 \%, 98.5: 1.5 \mathrm{er}^{[\mathrm{b}]}$

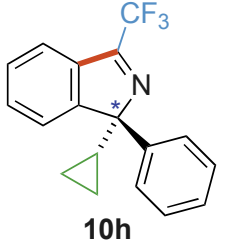

98\%, 93.5:6.5 er<smiles>[3H]N1CC([C@]2(c3ccccc3)N=C(C(F)(F)F)c3ccccc32)C1</smiles>

$84 \%, 83: 17 \mathrm{er}^{[\mathrm{a}]}$

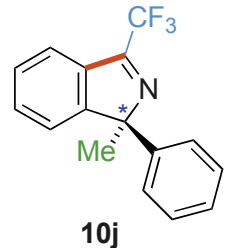

$97 \%, 72: 28$ er 
Scheme 10. Scope of the asymmetric synthesis of $1 \mathrm{H}$-isoindole with small substituents $\mathrm{R}$.

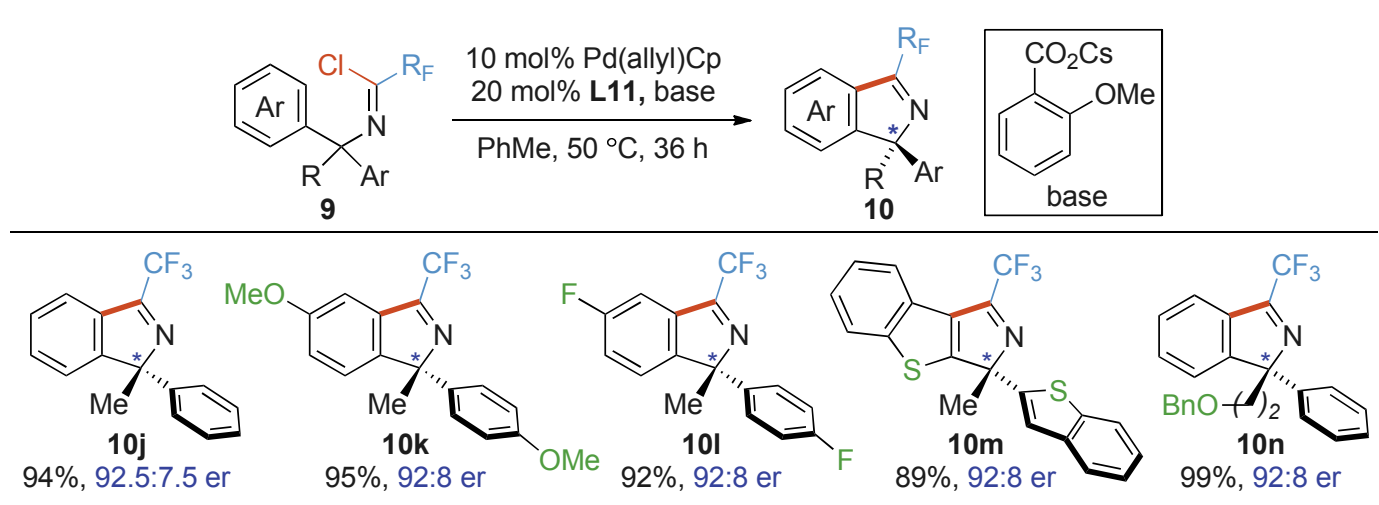

isoindole 10i was obtained in high yield and good enantioselectivity. However, when substrates that bear less bulky substituents, such as $\mathbf{9 j}$, were tested in the reaction, a significant decrease in enantioinduction was observed.

Identifying the set of reaction conditions suitable for the preparation of $1 \mathrm{H}$-isoindoles with small substituent $\mathrm{R}$ required considerable additional optimization efforts. Essentially, the combination of TADDOL-phosphoramidite ligand L11 with the cesium salt of ortho-anisic acid enabled highly enantioselective cyclization of the corresponding substrates (Scheme 10). As before, the reaction rate and the enantioselectivity were largely independent of the electronic characteristics of the functionalized arenes. Electron-neutral, electron-rich and electron-poor substrates all reacted well, furnishing the corresponding isoindoles $\mathbf{1 0 j}, \mathbf{1 0 k}$ and 10l, as well as benzothiophene substituted product $\mathbf{1 0 m}$. Furthermore, isoindole 10n featuring a synthetically valuable benzl ether chain was accessed in excellent yield and high enantioselectivity.

\section{Summary}

In conclusion, we developed a short and divergent route toward modular and tunable chiral phosphines filling the gap of accessible electron-rich monodentate ligands. These ligands were vital for the successful enantioselective $\mathrm{C}-\mathrm{H}$ alkenylations at ambient temperature, where the potential of ketene aminal phosphates as electrophilic partners in $\operatorname{Pd}(0)$-catalyzed transformations was showcased. Furthermore, we discovered that employing imidoyl chlorides as substrates in $\mathrm{C}\left(\mathrm{sp}^{2}\right)-\mathrm{H}$ functionalization resulted in the formation of highly functionalized perfluoroalkylated $1 \mathrm{H}$-isoindoles, which were previously inaccessible. Various substitution patterns were well tolerated, and high levels of stereocontrol were enabled by virtue of using a bulky phosphordiamidite ligand.

\section{Acknowledgements}

Daria Grosheva is grateful to Metrohm and the Swiss Chemical Society for being granted with the SCS-Metrohm Best Oral Presentation Award. We thank the Swiss National Science Foundation (no. 155967) for financial support.

Received: January 30, 2019

[1] a) J. Yamaguchi, A. D. Yamaguchi, K. Itami, Angew. Chem. Int. Ed. 2012 51,8960 ; b) J. He, M. Wasa, K. S. L. Chan, Q. Shao, J.-Q. Yu, Chem. Rev. 2017, 117, 8754; c) J. R. Hummel, J. A. Boerth, J. A. Ellman, Chem. Rev. 2017, 117, 9163; d) Z. Dong, Z. Ren, S. J. Thompson, Y. Xu, G. Dong, 2017, 117, 9333; e) K.Murakami, S. Yamada, T. Kaneda, K. Itami, Chem. Rev. 2017, 117,9302 .

[2] a) C. G. Newton, S.-G. Wang, C. C. Oliveira, N. Cramer, Chem. Rev. 2017, 117, 8908; b) T. G. Saint-Denis, R.-Y. Zhu, G. Chen, Q.-F. Wu, J.-Q. Yu, Science 2018, 359, eaao4798.

[3] a) S. Anas, A. Cordi, H. B. Kagan, Chem. Commun. 2011, 47, 11483; b) M. Nakanishi, D. Katayev, C. Besnard, E. P. Kündig, Angew. Chem. Int.
Ed. 2011, 50, 7438; c) D. Katayev, M. Nakanishi, T. Burgi, E. P. Kündig, Chem. Sci. 2012, 3, 1422; d) T. Saget, S. J. Lemouzy, N. Cramer, Angew. Chem. Int. Ed. 2012, 51, 2238; e) T. Saget, N. Cramer, Angew. Chem. Int. Ed. 2012, 51, 12842; f) E. Larionov, M. Nakanishi, D. Katayev, C. Besnard, E. P. Kundig, Chem. Sci. 2013, 4, 1995; g) T. Saget, N. Cramer, Angew. Chem. Int. Ed. 2013, 52, 7865; h) D. Katayev, E. Larionov, M. Nakanishi, C. Besnard, E. P. Kündig, Chem. Eur. J. 2014, 20, 15021; i) Z.-Q. Lin, W.Z. Wang, S.-B. Yan, W.-L. Duan, Angew. Chem. Int. Ed. 2015, 54, 6265; j) J. Pedroni, T. Saget, P. A. Donets, N. Cramer, Chem. Sci. 2015, 6, 5164; k) C. He, M. Hou, Z. Zhu, Z. Gu, ACS Catal. 2017, 7, 5316; 1) L. Yang, R. Melot, M. Neuburger, O. Baudoin, Chem. Sci. 2017, 8, 1344; m) L. Yang, M. Neuburger, O. Baudoin, Angew. Chem. Int. Ed. 2018, 57, 1394; n) R. Rocaboy, D. Dailler, O. Baudoin, Org. Lett. 2018, 20, 772; o) C. G. Newton, E. Braconi, J. Kuziola, M. D. Wodrich, N. Cramer, Angew. Chem. Int. Ed. 2018, 57, 11040.

[4] a) M. R. Albicker, N. Cramer, Angew. Chem. Int. Ed. 2009, 48, 9139; b) P. M. Holstein, D. Dailler, J. Vantourout, J. Shaya, A. Millet, O. Baudoin, Angew. Chem. Int. Ed. 2016, 55, 2805.

[5] a) J. Pedroni, M. Boghi, T. Saget, N. Cramer, Angew. Chem. Int. Ed. 2014 53, 9064; b) J. Pedroni, N. Cramer, Angew. Chem. Int. Ed. 2015, 11826

[6] a) J. Wang, D.-W. Gao, J. Huang, S. Tang, Z. Xiong, H. Hu, S.-L. You, Q. Zhu, ACS Catal. 2017, 7, 3832; b) J. Pedroni, N. Cramer, J. Am. Chem. Soc. 2017, 139, 12398; c) S. Luo, Z. Xiong, Y. Lu, Q. Zhu, Org. Lett. 2018, 20 , 1837.

[7] D. Grosheva, N. Cramer, ACS Catal. 2017, 7, 7417.

[8] T. Hayashi, Acc. Chem. Res. 2000, 33, 354.

[9] B. Saha, T. V. RajanBabu, J. Org. Chem. 2007, 72, 2357.

[10] K. C. Nicolaou, K. Namoto, Chem. Commun. 1998, 1757.

[11] a) J. W. Coe, Org. Lett. 2000, 2, 4205; b) F. L. Galbo, E. G. Occhiato, A. Guarna, C. Faggi, J. Org. Chem. 2003, 68, 6360

[12] J. Pedroni, N. Cramer, Chem. Commun. 2015, 51, 17647.

[13] B. J. Simmons, M. Hoffmann, J. Hwang, M. K. Jackl, N. K. Garg, Org. Lett. 2017, 19, 1910 .

[14] D. Grosheva, N. Cramer, Angew. Chem. Int. Ed. 2018, 57, 13644.

[15] a) K. Speck, T. Magauer, Beilstein J. Org. Chem. 2013, 9, 2048; b) B.-M. Swahn, K. Kolmodin, S. Karlström, S. von Berg, P. Söderman, J. Holenz, S. Berg, J. Lindström, M. Sundström, D. Turek, J. Kihlström, C. Slivo, L. Andersson, D. Pyring, D. Rotticci, L. Öhberg, A. Kers, K. Bogar, F. von Kieseritzky, M. Bergh, L.-L. Olsson, J. Janson, S. Eketjäll, B. Georgievska, F. Jeppsson, J. Fälting, J. Med. Chem. 2012, 55, 9346; c) G. E. Morse, T. P Bender, ACS Appl. Mater. Interfaces 2012, 4, 5055.

[16] a) C. G. Savarin, C. Grisé, J. A. Murry, R. A. Reamer, D. L. Hughes, Org. Lett. 2007, 9, 981; b) B. Hatano, K. Miyoshi, H. Sato, T. Ito, T. Ogata, T. Kijima, Tetrahedron Lett. 2010, 51, 5399; c) M. Kuroda, K. Kobayashi, Helv. Chim. Acta 2015, 98, 279.

[17] a) K. Tamura, H. Mizukami, K. Maeda, H. Watanabe, K. Uneyama, J. Org. Chem. 1993, 58, 32; b) K. Uneyama, J. Fluorine Chem. 1999, 97, 11.

[18] a) S. Purser, P. R. Moore, S. Swallow, V. Gouverneur, Chem. Soc. Rev. 2008, 37, 320; b) T. Liang, C. N. Neumann, T. Ritter, Angew. Chem. Int. Ed. 2013, 52,8214 .

[19] a) S. Fustero, J. Moscardó, M. Sánchez-Roselló, E. Rodríguez, P. Barrio, Org. Lett. 2010, 12, 5494; b) S. Fustero, I. Ibáñez, P. Barrio, M. A. Maestro, S. Catalán, Org. Lett. 2013, 15, 832; c) S. Fustero, L. Herrera, R. Lázaro, E. Rodríguez, M. A. Maestro, N. Mateu, P. Barrio, Chem. Eur. J. 2013, 19, 11776.

[20] P. A. Donets, N. Cramer, J. Am. Chem. Soc. 2013, 135, 11772.

[21] D. García-Cuadrado, P. de Mendoza, A. A. C. Braga, F. Maseras, A. M. Echavarren, J. Am. Chem. Soc. 2007, 129, 6880. 